\title{
MICROSTRUCTURE AND MECHANICAL PROPERTY DEVELOPMENT IN SUPERALLOY U720LI
}

\author{
David Ulrich Furrer and Hans-Jorg Fecht* \\ Ladish Co., Inc., PO Box 8902, Cudahy, WI 53110, USA \\ *Universität Ulm, Albert-Einstein-Allee 47, D-89081 Ulm, Germany
}

\begin{abstract}
$\underline{\text { Abstract }}$
Superalloy Udimet $720 \mathrm{LI}^{\mathrm{TM}}$ has been studied and implemented into many production applications. [1,2] Further work has been conducted to assess the nature of the microstructural evolution and mechanical property development in this alloy. This effort is focussed on thermal processing cycles to tailor gamma-prime distribution and grain boundary morphologies, and subsequent mechanical properties. The results of this work have been compared to previous studies and assessed with regard to basic physical metallurgy understanding of the observed microstructure/property relationships. A new thermal processing route has been established which will allow for an optimum balance in mechanical properties for this material for potential future applications.
\end{abstract}

\section{Experimental Procedure}

A three-phased experimental program was undertaken to study U720LI material. A laboratory phase was conducted on heat treated microspecimens. A property screening phase, which incorporated mechanical property test specimens to evaluate heat treatment cooling rates, was performed. A full scale forging demonstration and validation phase was also conducted to more completely assess the microstructure and mechanical property interactions in U720LI.

\section{Laboratory Heat Treat Studies}

To study the microstructural evolution in superalloy U720LI, laboratory experiments where performed to characterize the microstructure and phases present after various thermal treatments. Initial studies were performed on billet samples from both powder metallurgy $(\mathrm{P} / \mathrm{M})$ and cast and wrought ( $C \& W)$ (i.e. ingot metallurgy) materials. Laboratory thermal treatment studies focused on both subsolvus and supersolvus solution heat treatment cycles and aging treatments.

The specific chemistry for the U720LI materials investigated in this program is listed in Table $I$. The gamma-prime solvus for the $\mathrm{P} / \mathrm{M}$ and cast and wrought U720LI billet material was determined to be $1155^{\circ} \mathrm{C}$, and $1160^{\circ} \mathrm{C}$ respectively.

Table I. Chemistry of the U720LI material studied (w\%).

\begin{tabular}{|c|c|c|c|c|c|c|c|c|c|c|}
\hline & $\mathbf{C r}$ & $\mathbf{C o}$ & Ti & Al & Mo & W & Zr & C & B & Ni \\
\hline P/M & 16.26 & 14.73 & 5.05 & 2.50 & 3.01 & 1.27 & 0.036 & 0.023 & 0.018 & Rem. \\
\hline $\mathrm{C} \& W$ & 16.06 & 14.52 & 5.04 & 2.54 & 3.08 & 1.20 & 0.047 & 0.013 & 0.018 & Rem. \\
\hline
\end{tabular}

Billet slices of each material were sectioned by wire electric discharge machining (EDM) to produce $12.7 \times 12.7 \times 25.4$ $\mathrm{mm}$ heat treatment blocks. Holes $1.6 \mathrm{~mm}$ in diameter were drilled in the center of the $12.7 \times 12.7 \mathrm{~mm}$ face to a depth of $12.7 \mathrm{~mm}$ for insertion of a friction fit sheathed thermocouple.

Solution heat treatment studies were performed on the heat treatment blocks with thermocouples attached. Controlled cooling at different cooling rates was achieved by imposing different cooling media, such as air, oil and water, and by wrapping the blocks with various layers of insulating media to retard cooling to simulate large turbine disc-type components. $\mathrm{An}$ extensive matrix of heat treatment conditions were performed on the program samples, which included supersolvus and subsolvus solution cycles.

After solution heat treating, the samples were sectioned at the middle of the block, normal to the thermocouple hole for metallographic analysis and further aging studies. Aging studies were performed on select samples to determine the changes in phase types, quantities and morphologies.

\footnotetext{
Th Udimet is a registered trademark of Special Metals Corporation.
}

Superalloys 2000






\section{Property Screening Phase}

In addition to the heat treated metallographic samples, laboratory test bar samples were processed, mechanically tested and characterized. These samples are similar to the smaller block samples outlined above, but are much longer in size to accommodate machining mechanical test specimens from them after laboratory heat treatment. These cooling-rate test bars also had thermocouples inserted into one end to allow measurement of the exact cooling rate profile the bars experienced during the imposed heat treatment cycle. These samples were used to evaluate the effects of solution heat treat cycle and cooling rate on final elevated temperature tensile and creep properties.

Both cast and wrought and powder metallurgy U720LI were tested in this phase. Supersolvus solution treatments were performed to allow assessment of intermediate (P/M) and coarse $(\mathrm{C} \& W)$ structures. Table II lists the processing conditions given to each series of test bars.

Table II. Solution heat treatment cycles used for the mechanical property screening test samples. All samples were given a $760^{\circ} \mathrm{C} / 8 \mathrm{hrs} . / \mathrm{AC}+$ $649^{\circ} \mathrm{C} / 24 \mathrm{hrs} . / \mathrm{AC}$ age treatment.

\begin{tabular}{|l|l|l|}
\hline Series ID & \multicolumn{1}{|c|}{ Solution Heat } & \multicolumn{1}{|c|}{ Solution Cooling } \\
\hline $\mathrm{C} 15 / \mathrm{P} 15$ & $1168^{\circ} \mathrm{C}$ & Continuous Cooled \\
\hline $\mathrm{C} 26 / \mathrm{P} 26$ & $1168^{\circ} \mathrm{C}$ & Continuous Cooled \\
\hline $\mathrm{C} 37 / \mathrm{P} 37$ & $1168^{\circ} \mathrm{C}+1143^{\circ} \mathrm{C}$ & Continuous Cooled \\
\hline $\mathrm{C} 48 / \mathrm{P} 48$ & $1168^{\circ} \mathrm{C}$ & Step-Cooled \\
\hline
\end{tabular}

\section{Full-Scale Forging Evaluation}

The forging phase of this program was designed to develop and expand upon the microstructure / mechanical property relationships for P/M U720LI material. C\&W U720LI processed by a supersolvus solution cycle did not show a capability of developing a good balance of tensile and creep properties and was not pursued after the property screening phase.

For this effort, $229 \mathrm{~mm}$ diameter by $132 \mathrm{~mm}$ tall $\mathrm{P} / \mathrm{M}$ U720LI billet material was isothermally forged into a $427 \mathrm{~mm}$ diameter $\times 38 \mathrm{~mm}$ thick pancake material. The chemistry of this material is listed in Table III.

Table III. Chemistry of the P/M U720LI billet material used for the full-scale forging efforts (wt.-\%).

\begin{tabular}{cccccccc}
$\mathrm{Cr}$ & $\mathrm{Co}$ & $\mathrm{Ti}$ & $\mathrm{Mo}$ & $\mathrm{Al}$ & $\mathrm{W}$ & $\mathrm{Fe}$ & $\mathrm{Zr}$ \\
\hline 16.35 & 14.78 & 5.01 & 3.00 & 2.41 & 1.35 & 0.09 & 0.031 \\
$\mathrm{~B}$ & $\mathrm{C}$ & $\mathrm{Mn}$ & $\mathrm{Si}$ & $\mathrm{Cu}$ & $\mathrm{P}$ & $\mathrm{S}$ & $\mathrm{N} 2$ \\
\hline 0.017 & 0.021 & $<0.02$ & $<0.06$ & 0.02 & $<0.010$ & 0.0003 & 0.0017
\end{tabular}

Four different heat treatments were given to the full-scale forged material. These heat treatments were aimed at assessing the development of optimum grain boundary and gamma-prime morphologies. All solution heat treat cycles are aimed at developing a uniform ASTM 7 grain size. The solution heat treatment cycles are graphically shown in Figure 1. Each solution cycle was numbered to correspond to the forged sample serial number. Solution cycle 1001 was aimed at developing large grain boundary serrations along with primary gamma-prime. Solution cycle 1002 was aimed at developing little grain boundary serrations and very fine secondary gamma-prime. Solution cycle 1003 was aimed at developing serrated grain boundaries with no primary gamma-prime. Solution cycle 1004 was aimed at developing serrated grain boundaries with fine gammaprime.

Three different aging practices were performed on each solution heat treated material to further assess the effect of aging treatments on mechanical property response. Table IV lists the aging cycles used.

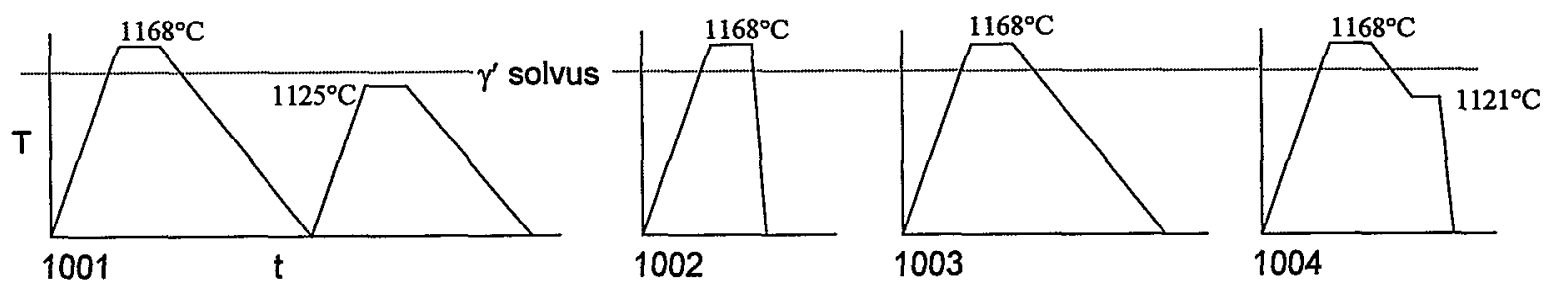

Figure 1. Schematic time temperature plots that show the solution heat treatment cycles relative to the gamma-prime solvus, which were utilized for the full-scale forging phase. 
Tablc IV. Aging cycles given to the full-scale forged samples.

\begin{tabular}{|c|l|l|}
\hline Age & Cycle 1 & Cycle 2 \\
\hline A & $843^{\circ} \mathrm{C} / 8 \mathrm{hrs} . / \mathrm{FAQ}$ & $760^{\circ} \mathrm{C} / 16 \mathrm{hrs} . / \mathrm{AC}$ \\
\hline $\mathrm{B}$ & $760^{\circ} \mathrm{C} / 16 \mathrm{hrs} . / \mathrm{AC}$ & -- \\
\hline $\mathrm{C}$ & $649^{\circ} \mathrm{C} / 24 \mathrm{hrs} . / \mathrm{AC}$ & $760^{\circ} \mathrm{C} / 16 \mathrm{hrs} . / \mathrm{AC}$ \\
\hline
\end{tabular}

\section{$\underline{\text { Results }}$}

\section{Laboratory Heat Treat Studies}

Optical and electron microscopy was performed on the laboratory heat treat samples. Grain size, gamma-prime size and morphology, and grain boundary morphology features were fully characterized as functions of solution

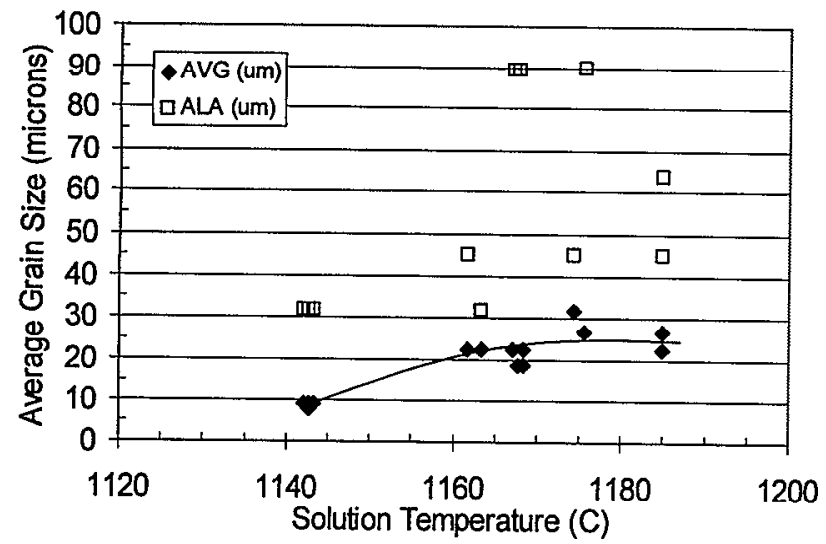

Figure 2. Plot of grain size as a function of solution heat treatment temperature for $A$ ) $P / M$ and B) $C \& W$ U720LI material.

The grain boundary morphology of supersolvus solution heat treated samples was seen to change as a function of cooling rate. Figure 4 shows photomicrographs of $\mathrm{P} / \mathrm{M}$ U720LI grain boundaries after two different cooling rates. All of the grain boundaries of supersolvus solution heat heat treatment temperature and cooling rate. The grain growth behavior of the powder metallurgy and ingot metallurgy materials are distinctly different. Figure 2 shows grain growth plots for both materials as a function of solution temperature.

Light and electron optic metallography performed on the laboratory heat treatment specimens revealed a strong cooling rate / gamma-prime size dependence. Figure 3 shows example photomicrographs, which show this correlation. Secondary gamma-prime size measurements were performed on carefully prepared scanning electron microscope specimens. Supplemental measurements were conducted on select samples using transmission electron microscopy. The TEM measurements confirmed the measurements performed by the SEM evaluation technique.

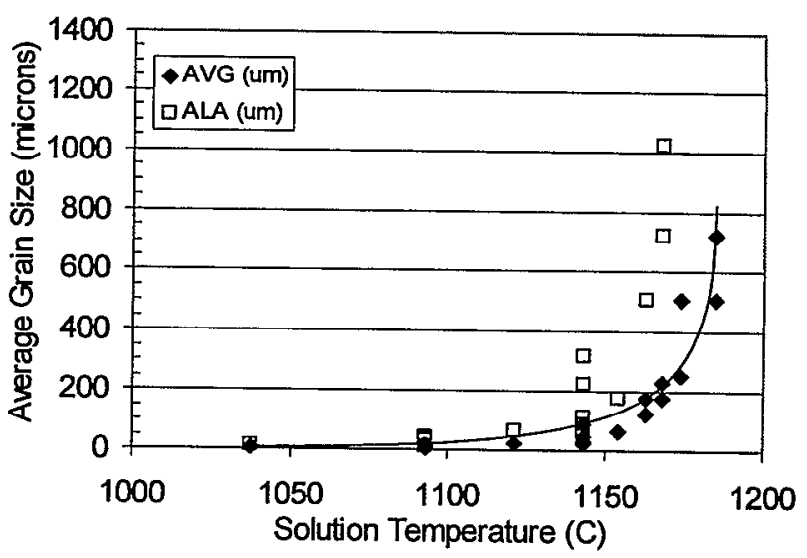



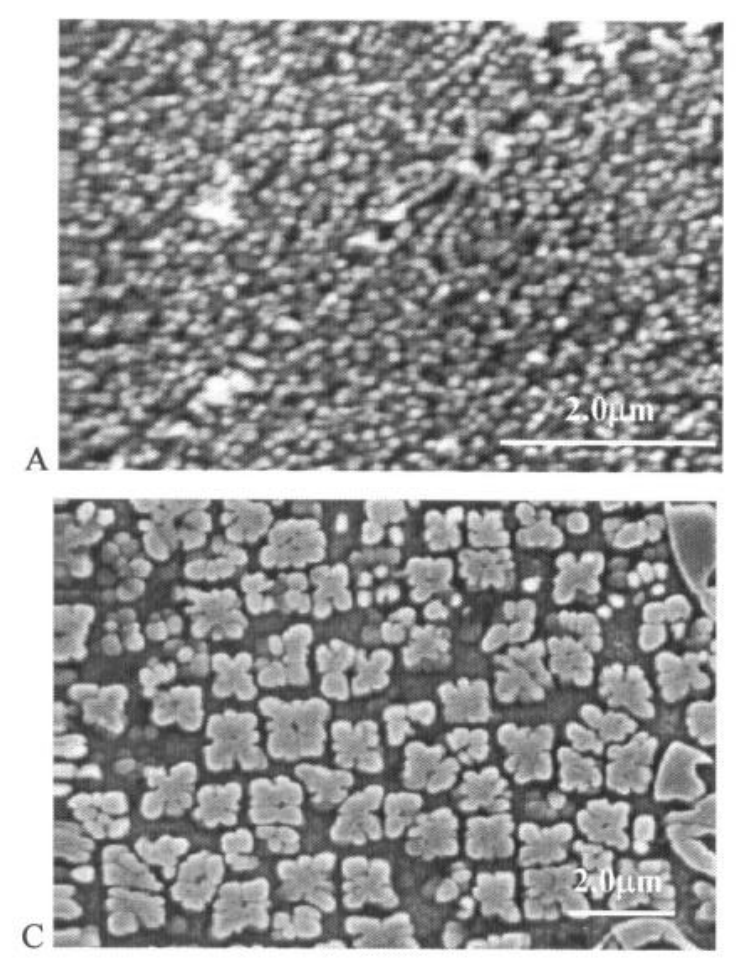
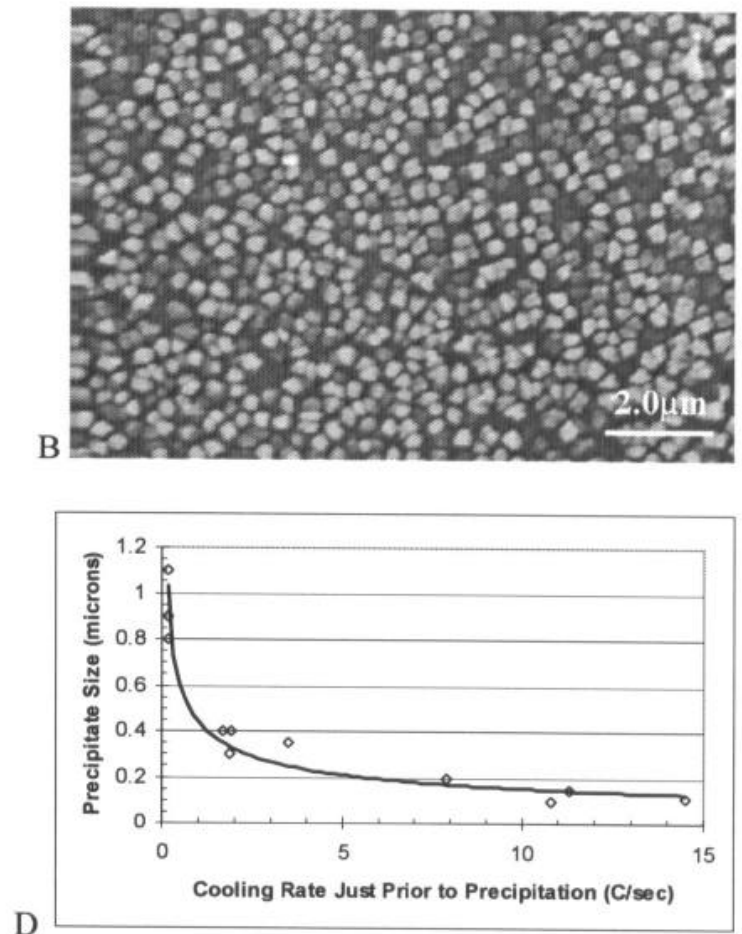

Figure 3. Photomicrographs of supersolvus solution heat treated P/M U720LI samples cooled at A) $12.7^{\circ} \mathrm{C} / \mathrm{sec}$, B) $\left.1.3^{\circ} \mathrm{C} / \mathrm{sec}, \mathrm{C}\right) 0.12^{\circ} \mathrm{C} / \mathrm{sec}$, and D) a plot expressing gamma-prime size as a function of cooling rate.
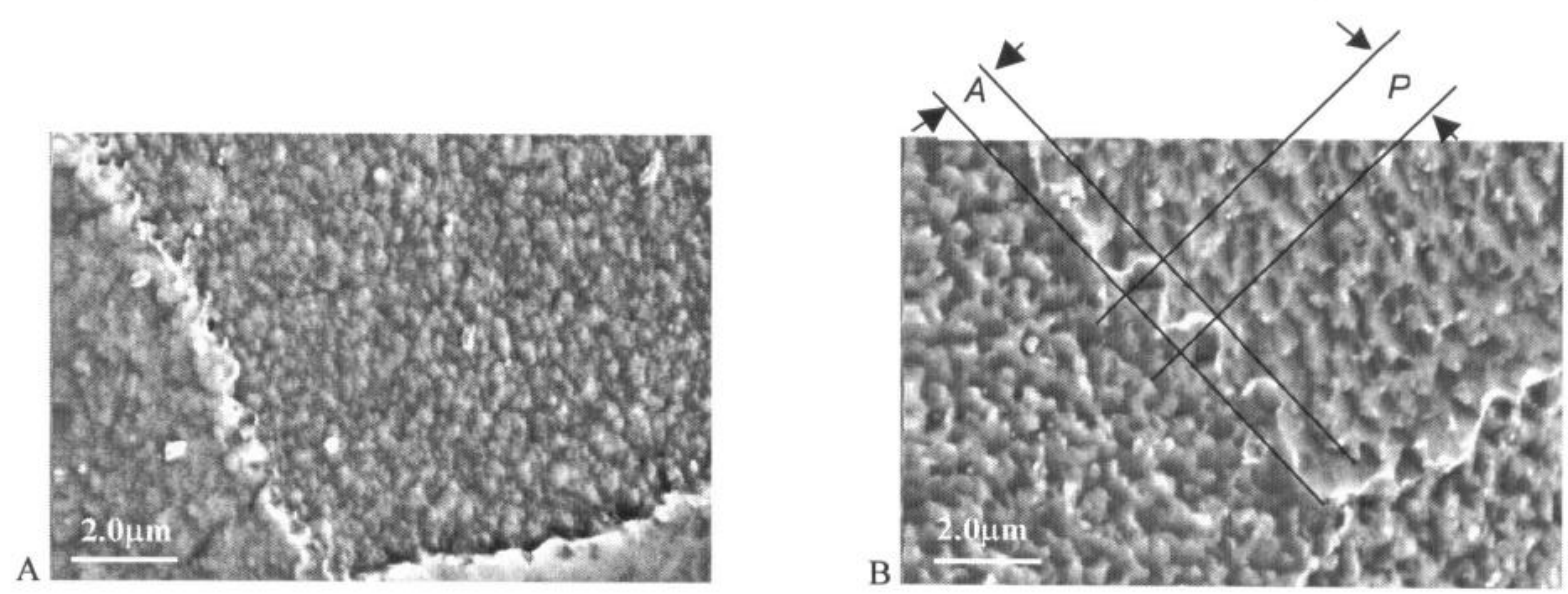

Figure 4. Serrated grain boundary morphologies of P/M U720LI material supersolvus solution treated and cooled at A) $12.7^{\circ} \mathrm{C} / \mathrm{sec}$ and B) $1.3^{\circ} \mathrm{C} / \mathrm{sec}$. $A$ and $P$ represent the measurements taken to assess serration amplitude and period respectively. 


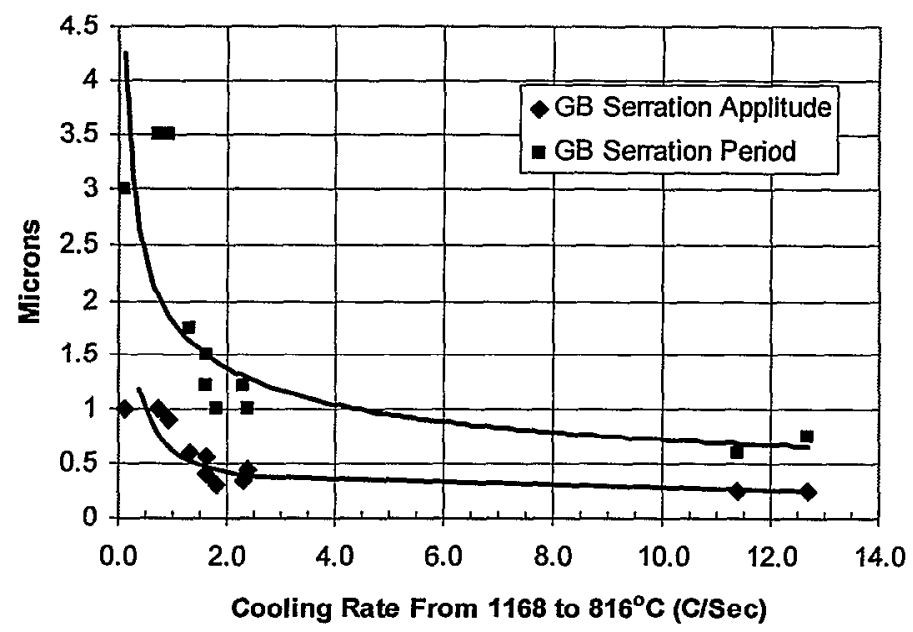

Figure 5. Plot of grain boundary serration amplitude for supersolvus solution treated P/M U720LI as a function of cooling rate.

Electrolytic extractions were performed on all laboratory heat treatment samples to assess the formation of carbide and boride phases as a result of the various thermal treatments. Samples were evaluated in the solution heat treated as well as aged condition. The as-solution heat treated samples allowed an estimation of the $\mathrm{M}_{23} \mathrm{C}_{6}$ and $\mathrm{M}_{3} \mathrm{~B}_{2}$ phase solvus temperatures as being between $1030^{\circ} \mathrm{C}$ $1040^{\circ} \mathrm{C}$ and $1060^{\circ} \mathrm{C}$ respectively.

The cast and wrought U720LI material contained large primary carbides [1], whereas the powder metallurgy material only exhibited relatively fine and uniform carbide precipitates. The X-ray diffraction patterns from the cast and wrought material also exhibited two primary carbide phases with distinctly different lattice parameters. It is believed that one is an MC carbide and the other an $\mathrm{M}(\mathrm{C}, \mathrm{N})$ carbo-nitride phase.

Relative fractions of carbide and boride phases were estimated by comparison of the heights of the strongest peak from each phase diffraction pattern. For all as- solution heat treated samples, $\mathrm{MC}$ carbides were the most predominant. The amount of $\mathrm{M}_{23} \mathrm{C}_{6}$ and $\mathrm{M}_{3} \mathrm{~B}_{2}$ increased with decreased cooling rate, and was seen to exceed the amount of primary carbide at the very slowest solution cooling rates examined. Aging also increased the amount of $\mathrm{M}_{23} \mathrm{C}_{6}$ and $\mathrm{M}_{3} \mathrm{~B}_{2}$, but $\mathrm{MC}$ was still the most predominant carbide/boride phase after each aging treatment except for the $843^{\circ} \mathrm{C}$ age, where $\mathrm{M}_{23} \mathrm{C}_{6}$ phase content exceeded that of the primary carbide.

\section{Property Screening Phase}

The mechanical property results for the test bar samples are shown in Table $V$. There is a strong mechanical property dependence on solution cooling rate, as seen for both materials. The tensile properties of the $\mathrm{P} / \mathrm{M}$ material are clearly superior to those of the cast and wrought samples, but conversely the cast and wrought material exhibited the best creep resistance for the same thermal treatments.

Table V. Results from the mechanical property screening tests. The tensile tests were conducted at $538^{\circ} \mathrm{C}$ and the creep-rupture condition used was $704^{\circ} \mathrm{C} / 690 \mathrm{MPa}$.

\begin{tabular}{|c|c|c|c|c|c|c|c|}
\hline ID & $\begin{array}{c}\text { Cooling } \\
\text { Rate } \\
\left({ }^{\circ} \mathrm{C} / \mathrm{sec}\right)\end{array}$ & $\begin{array}{c}\text { Grain Size } \\
\text { (ASTM \#) }\end{array}$ & $\begin{array}{c}\text { YS } \\
(\mathrm{MPa})\end{array}$ & $\begin{array}{c}\text { UTS } \\
(\mathrm{MPa})\end{array}$ & $\% \mathrm{E}$ & $\% \mathrm{RA}$ & $\begin{array}{c}\text { Hrs. to } \\
\text { Rupture }\end{array}$ \\
\hline C15 & 0.68 & 0.5 & 755 & 1138 & 14.7 & 16 & 509 \\
\hline C26 & 5.25 & 1.5 & 948 & 1217 & 9.7 & 13.8 & 912 \\
\hline C37 & $0.67 / 0.9$ & 1.5 & 810 & 1258 & 16.6 & 19.9 & 635 \\
\hline C48 & 0.74 & 1.0 & 807 & 1258 & 15.8 & 18.5 & 554 \\
\hline P15 & 0.68 & 7.5 & 914 & 1431 & 20.6 & 25.8 & 250 \\
\hline P26 & 4.46 & 7.5 & 1100 & 1569 & 13.2 & 16 & 391 \\
\hline P37 & $0.5 / 0.73$ & 7 & 938 & 1458 & 22 & 24.5 & 252 \\
\hline P48 & 0.74 & 8 & 965 & 1472 & 18.5 & 19.2 & 256 \\
\hline
\end{tabular}


The grain size that resulted after the heat treatment of each specimen was also measured and is listed in Table V. These average grain sizes are consistent with those observed in the laboratory heat treatment microspecimens. It is easy to understand that the very large difference in the mechanical properties between the $\mathrm{P} / \mathrm{M}$ and $\mathrm{C} \& \mathrm{~W}$ samples stems from the large difference in grain size. Because cast and wrought material can not be effectively processed to intermediate grain sizes (ASTM 6-8), and the results from property screening tests were so poor, this material pedigree was not carried into the full-scale forging phase of this program.

\section{Full-Scale Forging Evaluation}

The microstructure from the full-scale forged P/M U720LI materials is shown in Figures 6 and 7. The intentional variations in gamma-prime size and grain boundary morphology between each sample can be clearly seen.
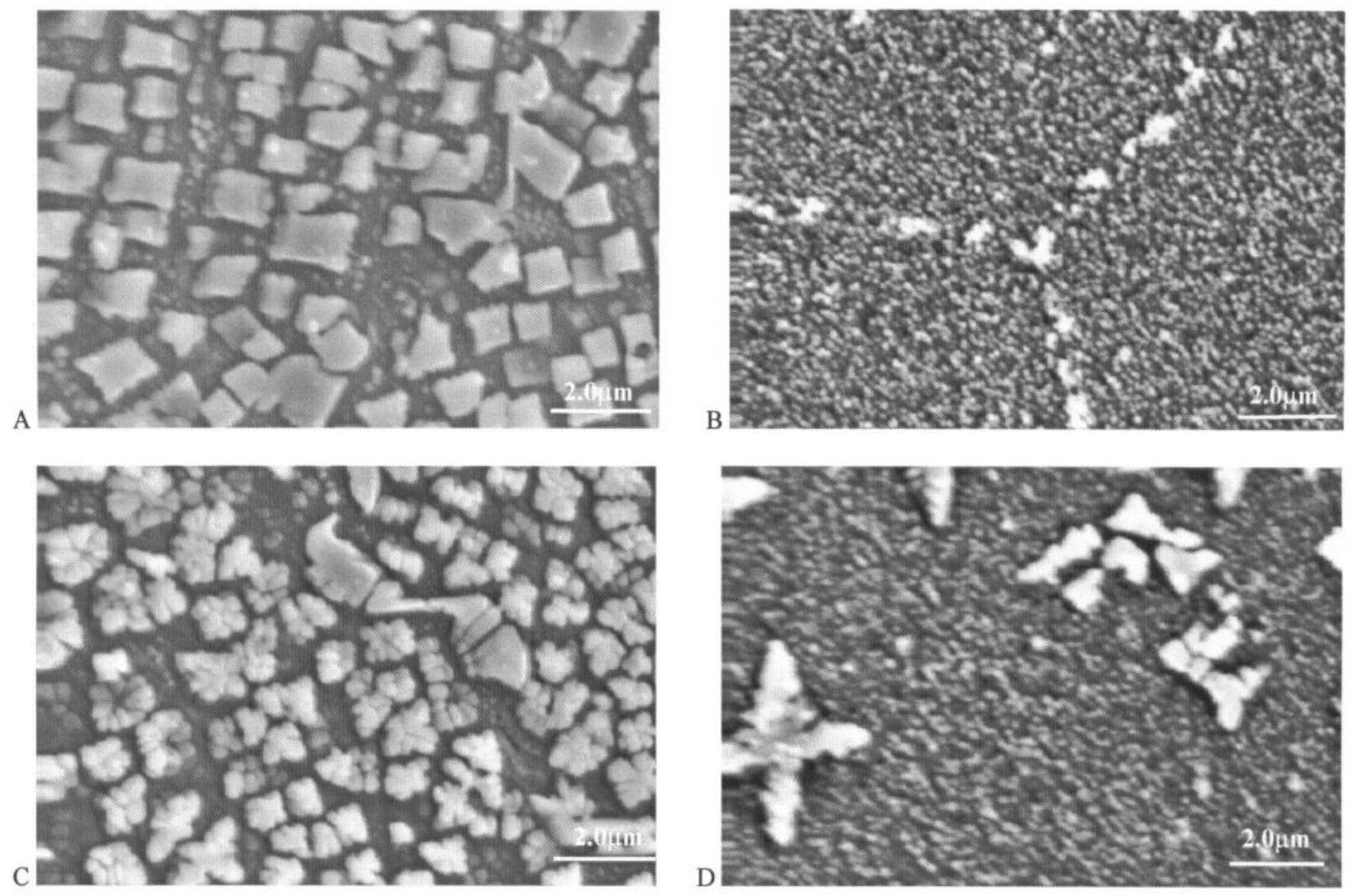

Figure 6. Photomicrographs of the secondary gamma-prime particles within S/N-1001 (A), S/N-1002 (B), $\mathrm{S} / \mathrm{N}-1003$ (C), and S/N-1004 (D). 

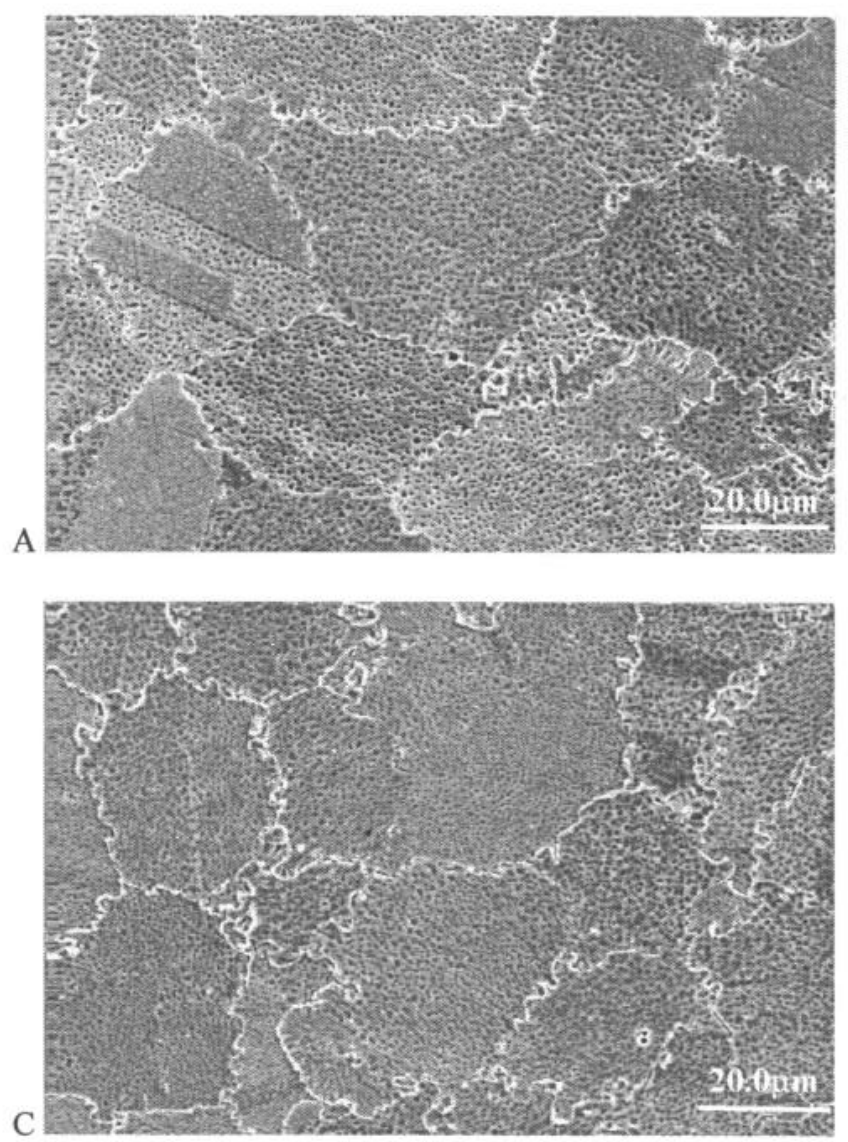
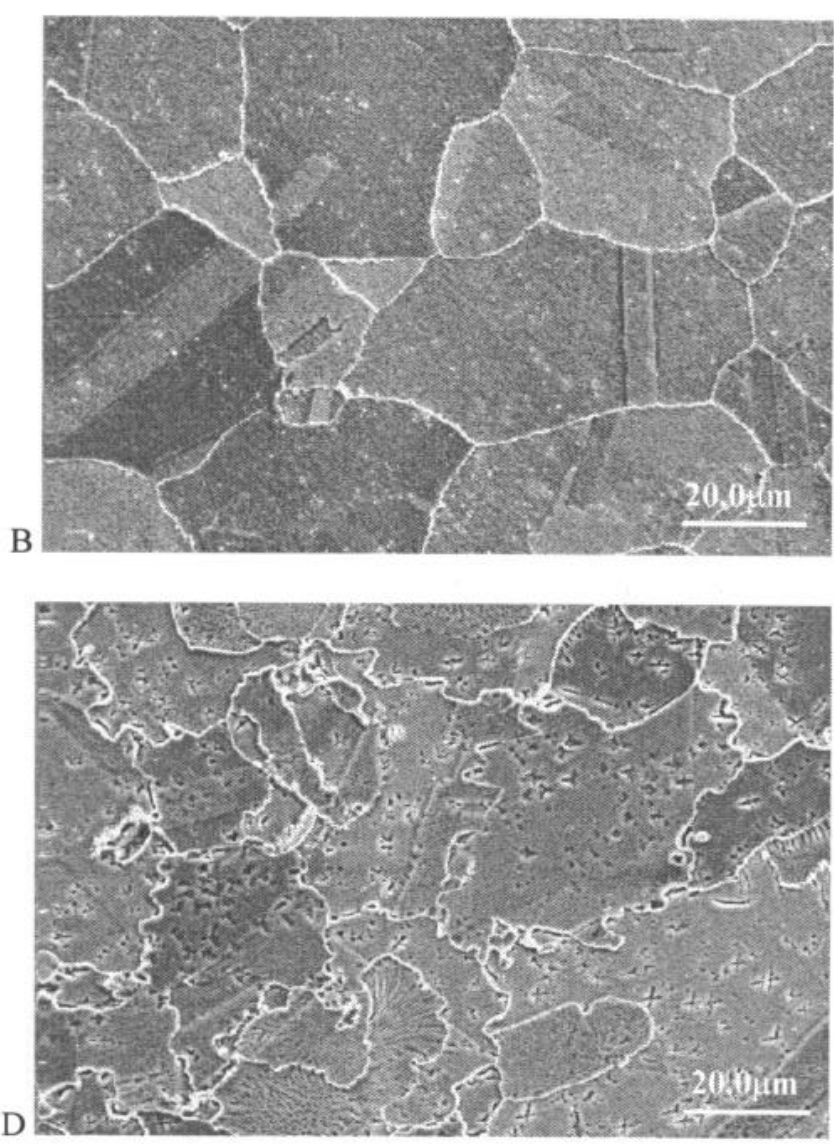

Figure 7. Photomicrographs of the grain boundary morphologies for S/N-1001 (A), S/N-1002 (B), S/N1003 (C), and S/N-1004 (D).

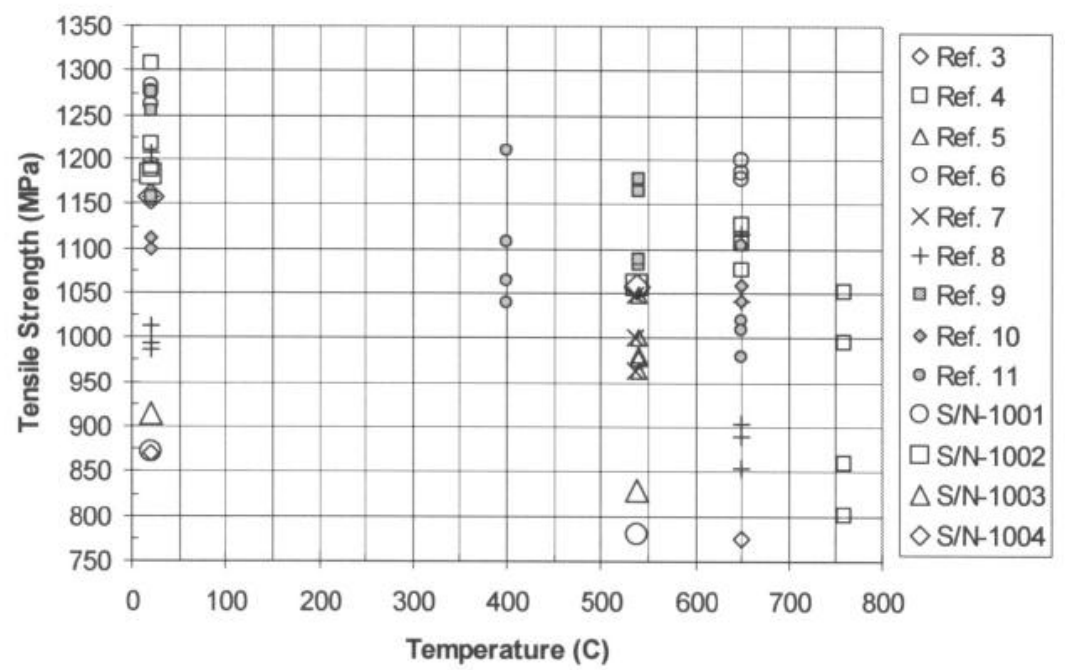

Figure 8. Average tensile properties from the full-scale forged and heat treated U720LI samples, along with literature data on U720 and U720LI material. 
The average tensile properties from each of the full-scale samples are shown in Figure 8. The average creep-rupture properties from each sample are presented in Figure 9. This Larsen-Miller plot shows that the material optimized for maximum grain boundary serration and finest secondary gamma-prime size results in the best creep properties. This material is seen to have greater creeprupture resistance compared to other U720LI and U720 disc materials and is even approaching the properties of coarse grain U720 blade material.

To assess the fracture resistance behavior of the full-scale samples, room temperature charpy impact tests were conducted. Figure 10 shows the results from this dynamic crack propagation screening test.

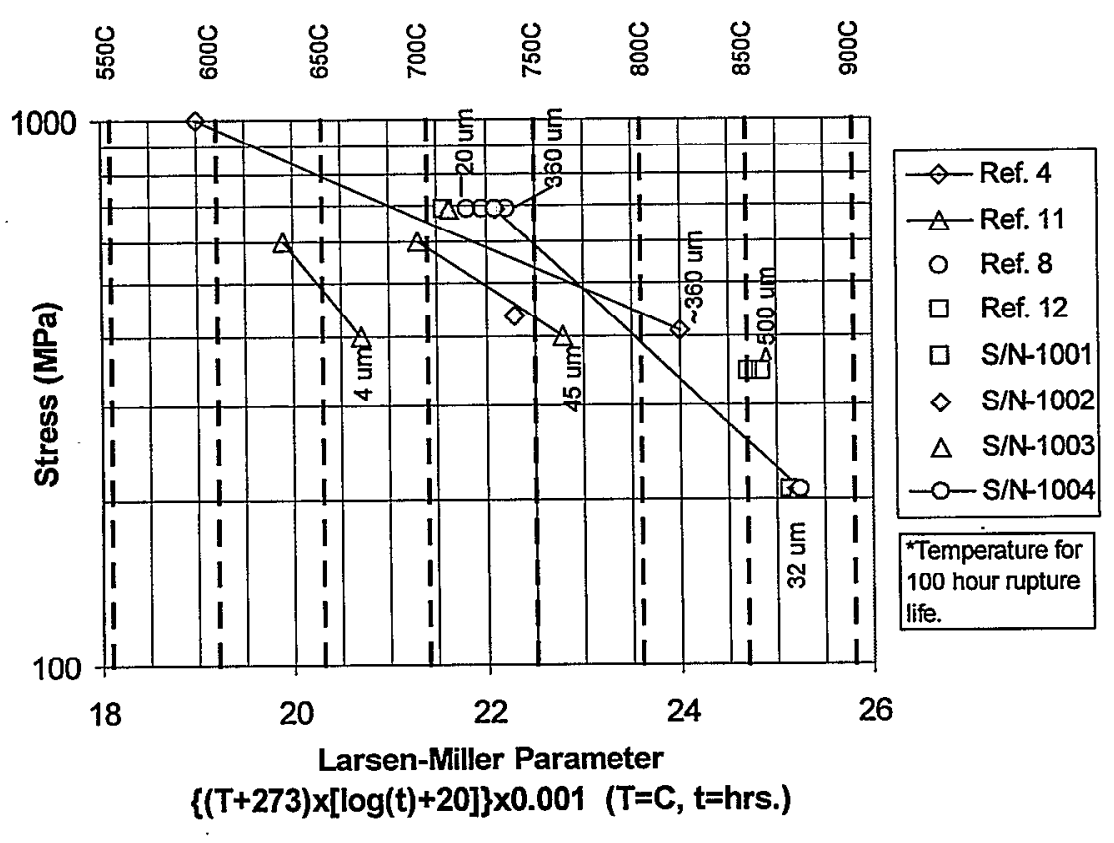

Figure 9. Larsen-Miller creep-rupture plot of the full-scale forged and heat treated U720LI samples, along with literature data for U720 and U720LI material.

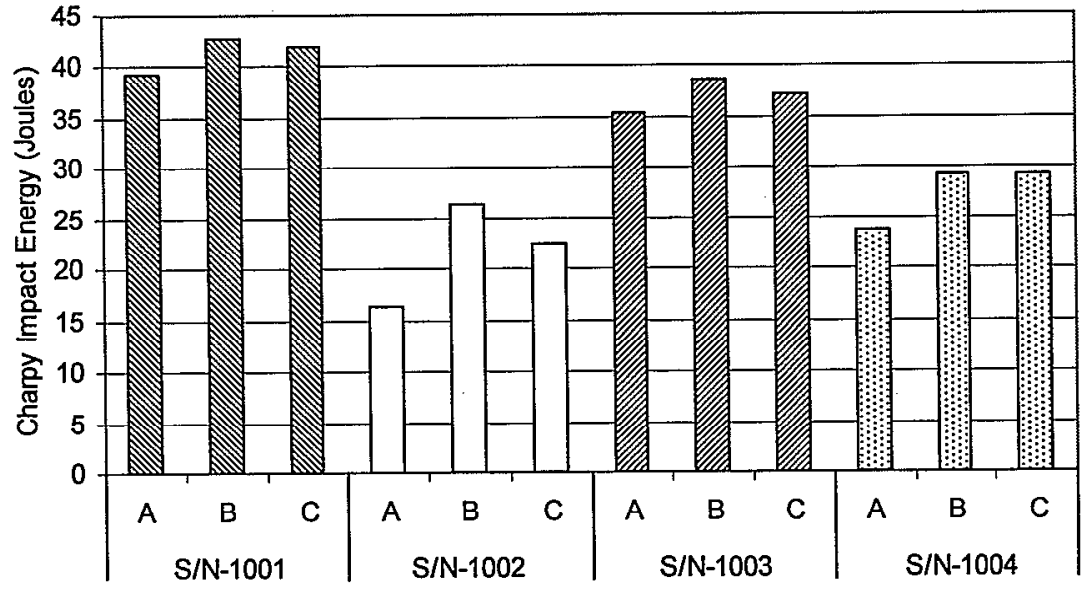

Age Temperature: A - 843C/760C B - $760 \mathrm{C}$ C - $649 \mathrm{C} / 760 \mathrm{C}$

Figure 10. Graph of the average charpy impact energies for each full-scale forged sample. 


\section{Discussion}

Equations in the form of the arrhenius rate equation can been developed to describe the grain growth behavior of $\mathrm{C} \& \mathrm{~W}$ and P/M U720LI. The equations developed in this program are as follows:

$$
\begin{aligned}
& \mathrm{d}^{1.5}-\mathrm{d}_{\mathrm{o}}^{1.5}=5.95 \times 10^{45} \mathrm{t} \exp (-1273900 / \mathrm{RT}) \quad[\mathrm{C} \& \mathrm{~W}] \\
& \mathrm{d}^{5.4}-\mathrm{d}_{\mathrm{o}}^{5.4}=2.37 \times 10^{91} \mathrm{t} \exp (-2432900 / \mathrm{RT}) \quad[\mathrm{P} / \mathrm{M}]
\end{aligned}
$$

These equations are shown in Figures 2, along with the experimental data. It can be seen that the developed equations fit the observed gain growth behavior well.

The gamma-prime size was seen to be closely related to cooling rate. It has been previously reported that very little difference in precipitation undercooling was observed for this material. [2] It is believed that the secondary gammaprime grows after initial nucleation and therefore the gamma-prime size must be a diffusion controlled process. Since diffusion distance is proportional to the square root of the diffusivity and time, an expression of this form has been developed which shows extremely good correlation with the observed data. In this expression, cooling rate contains a factor of time, while the remaining factors are related to a function of the material diffusivity. This equation is shown in Figure 3 along with the measured experimental data.

$$
d=0.4425 x(C)^{-0.4506}
$$

The formation of serrated grain boundaries in U720LI is very interesting. It was seen from detailed metallographic analysis that the serrated grain boundaries are caused by the formation and growth of grain boundary gamma-prime. The relationships between the grain boundary serration and gamma-prime sizes versus cooling rate are also very similar, lending further evidence that growth of grain boundary gamma-prime is the cause of the grain boundary serrations.

The mechanical properties of U720LI can be linked to gamma-prime size through an analysis of dislocation interactions and predictions of critical resolved shear stress. This approach has been previously performed on subsolvus processed C\&W U720LI. [13] Using this approach with supersolvus processed U720LI results in a similar relationship between gamma-prime size and theoretical critical resolved shear stress. Theoretical estimations of tensile strength have been calculated based on knowledge of the critical resolved shear stress. A proportionality factor (the Taylor factor) relates the critical resolved shear stress to observed tensile strength values.
From this approach, it has becn scen that theorctical and experimental strength values correlate well.

The results from the creep and charpy impact tests show that the gamma-prime size have a large influence on these mechanical properties as well. Additionally, grain boundary serrations appear to also play a role in these properties. While S/N-1002 and S/N-1004 had nearly identical tensile properties, S/N-1004 (sample with large grain boundary serrations) exhibited improved impact resistance.

The age process used during the heat treatment of U720LI has been shown to be critical in the development of optimum mechanical properties. The single step aging treatment exhibited the best properties for all solution heat treatments and cooling conditions. This is believed to be due to a combination of optimum growth of the fine gamma-prime particles and optimum distributions of borides and carbides. It was seen that the high temperature aging cycle resulted in extensive $\mathrm{M}_{23} \mathrm{C}_{6}$ formation, and gamma-prime particles growth. These changes are seen to be very deleterious to the final component mechanical properties.

\section{Conclusions}

- This program resulted in a better understanding of the U720LI phases, phase relationships and formation kinetics, and microstructure mechanical property relationships.

- A model has been developed for the prediction of gamma grain growth, gamma-prime precipitate size and grain boundary serration morphology.

- A correlation between microstructure and mechanical properties has been established.

- A new thermal processing cycle has been developed to produce an intermediate grain size U720LI material with reduced residual stresses, and optimized mechanical properties.

- The new thermal processing cycle includes a supersolvus solution cycle, a stepped cooling rate, and a single aging treatment. 


\section{$\underline{\text { References }}$}

1. D. Furrer and H. Fecht, "Superalloys for Turbine Disc Applications", JOM, January, 1999, pp. 14-18.

2. D.U. Furrer and H.-J. Fecht, " $\gamma$ ' Formation in Superalloy U720LI", Scripta Mat., Vol.40, No.11, pp. 1215-1220, 1999.

3. L.S. Buslavsky, et. al., "Improvement of the Granulated Nickel Alloy EP741NP for the Purpose of an Increase in the Mechanical and Operating Characteristics", Technology Of Light Alloys, Vol. 2, VILS, Russia, 1997, pp. 24-26.

4. F.E. Sczerzenie and G.E. Maurer, "Development of Udimet 720 for High Strength Disk Applications", Superalloys 1984, eds., Gell, et. al., TMS, 1984, pp. 573-582.

5. J.F. Radavich and J. Hyzak, "Effect of Processing and Thermal Treatment on Alloy 720", Proceedings of the Tenth International Conference on Vacuum Metallurgy, Vol. 1, Specialty Melting, Beijing, China, June 11-15, 1990.

6. S.Bashir and M. Thomas, "Effect of Interstitial Content on High Temperature Fatigue Crack Propagation and Low Cycle Fatigue of Alloy 720", Superalloys 1992, eds., S.D. Antolovich, et. al., TMS, 1992, pp. 747- 755 .

7. J.M Hyzak, et. al., ., "The Microstructural Response of As-HIP P/M U-720", Superalloys 1992, eds., S.D. Antolovich, et. al., TMS, 1992, pp. 93-102.

8. K.R. Bain, et. al., "Development of Damage Tolerant Microstructures in Udimet 720", Superalloys 1988, eds., S. Reichman, et. al., TMS, 1988, pp. 13-22.

9. K.A. Green, J.A. Lemsky and R.M. Gasior, "Development of Isothermally Forged P/M Udimet 720 for Turbine Disk Applications", Superalloys 1996, eds., R.D. Kissinger, et. al., TMS, 1996, pp. 697-703.

10. D.J. Bryant and G. McIntosh, "The Manufacture and Evaluation of a large Turbine Disc in Cast and Wrought Alloy 720LI", Superalloys 1996, eds., R.D. Kissinger, et. al., TMS, 1996, pp. 713-722.

11. H. Hattori, M. Takekawa, D. Furrer and R. Noel, "Evaluation of P/M U720 for Gas Turbine Engines Disk Application", Superalloys 1996, eds., R.D. Kissinger, et. al., TMS, 1996, pp. 705-711.
12. I. Tsuji and $\mathrm{H}$. Itoh, "Long Term Stability of Ni-Base Superalloy U720 Bar and Blade for Gas Turbine Blades", Transactions of the Iron and Steel Institute of Japan, Vol. 22:4, 1982, p. B-112.

13. M.P. Jackson, R.C. Reed, Material Science and Engineering, A259, 85, (1999). 